\title{
R6. Ps. Augustinus
}

\section{[Dialogus inter Mariam et animam]}

Dyalogus Augustini inter sanctam animam et beatam virginem Mariam / Dyalogus inter beatam virginem et animam fidelem / Dialogus inter beatam virginem et animam fidelem / Augustinus in dyalogo inter sanctam animam et Mariam de passione Domini / De Maria et anima / Tractatus beati Augustini de passione Domini / Contemplatio animae et planctus Sanctae Mariae / De passione Domini

Studie: Kapitel 4.5.

Titel: Der Titel variiert stark in der Überlieferung. Am häufigsten findet sich die Bezeichnung Dialogus (auch in den älteren Handschriften) und die Erwähnung beider Gesprächspartnerinnen. Vereinzelt finden sich die Bezeichnungen Tractatus, Contemplatio und Planctus.

Incipit: O animae fideles sponsae Iesu Christi fletum deducite donec sponsus...

Explicit:... virgo praeclara, memor esto mei apud filium tuum cum quo tibi laus est et gloria in saecula.

Autor: In der Überlieferung wird der Text meistens Augustinus zugeschrieben. Der Autor des Dialogus benutzte eindeutig als Quelle den sogenannten Bernhardstraktat (auch Quis dabit genannt), der zum Teil wörtlich zitiert wird. Der Bernhardstraktat besteht aus Ausschnitten einer Predigtreihe des Zisterzienserabtes Oglerius von Lucedio oder von Trino (1136-1214), die, aus ihrem ursprünglichen Kontext gelöst, als Planctus zahlreich überliefert sind (vgl. A7). In der Überlieferung wird der Bernhardstraktat Augustin, Anselm oder Bernhard von Clairvaux zugeschrieben. Es ist möglich, dass der unbekannte Autor des Dialogus eine Vorlage mit Augustinus-Zuschreibung hatte, die er in seiner Bearbeitung beibehalten hat. Es gibt keine Hinweise auf seine Identität.

Datierung: Die Predigt des Oglerius von Trino, aus der der Bernhardstraktat herausgelöst wurde, wurde nach Einschätzung von Barré (255) vor 1205 geschrieben. Der Bernhardstraktat zirkulierte dann bereits im 13 . Jh. (dazu ebenfalls Barré; In principio nennt mehrere Handschriften aus diesem Jahrhundert). Den Terminus ante quem geben die Handschriften des Dialogus in Erfurt (erste Hälfte des 14. Jhs.) und in Pommersfelden (13./14. Jh.). Der Dialogus wurde demzufolge im Verlauf des 13. Jhs. verfasst. Eine genauere Datierung ist nicht möglich. 
Inhalt: Der Text beginnt mit einer kurzen Aufforderung an die gläubigen Seelen, das Leiden Christi zu beweinen und Maria nach der Leidensgeschichte zu fragen, denn sie sei damals anwesend gewesen und habe alles gesehen und gehört. Die Seele bittet Maria, ihren Schmerz zu schildern, um ihn nachempfinden zu können. Maria kann selber nicht weinen, da sie bereits im Himmel ist, sie ist aber bereit, ihr damaliges Leid auszumalen. Ihre Erzählung geht kaum auf äußere Begebenheiten ein, sie beschreibt vor allem ihre Gefühle beim Leiden ihres Sohnes. Ein kurzes Gespräch mit dem Gekreuzigten, in dem sie wünscht, ebenfalls zu sterben, und in dem ihr Sohn sie Johannes anvertraut, wird von Maria in direkter Rede wiedergegeben. Nach dem Tod Jesu habe sie versucht, ihn zu umarmen und zu küssen. Als ihr Sohn vom Kreuz heruntergenommen wurde, sei er ihr in die Arme gelegt worden, und sie habe sich kaum von ihm trennen können. Schließlich schildert sie das Mitleid der Anwesenden. Ihre Erzählung wird häufig von Ausrufen der Anima unterbrochen, mit denen sie ihr Mitgefühl und ihre Liebe für Christus betont. Maria redet sie mit sponsa filii mei oder mit anima fidelis an.

Editionen: Unediert.

\section{Literatur:}

Barré, Henri, „Le Planctus Mariae attribué à St. Bernard“, Rérue de mystique et d'ascétique 28 (1952), 243-266.

Eggers, Hans, Art. „Bernhardstraktat“, VL 1 (1978), 793-794; VL 11 (2004), 245-246.

\section{Überlieferung:}

Aus Römer, Franz, Die handschriftliche Überlieferung der Werke des Heiligen Augustinus. Band III: Polen, Wien 1973, 138:

Częstochowa, Biblioteka Paulinów, Cod. II 27, 15. Jh., fol. 85r-88v. Titel: Tractatus beati Augustini de passione Domini.

Aus Kurz, Rainer, Die handschriftliche Überlieferung der Werke des Heiligen Augustinus. Band V/1 Bundesrepublik Deutschland und Westberlin. Werkverzeichnis, Wien 1976, 490:

Aschaffenburg, StiftsB, Perg. 25, 15. Jh., fol. 111v-114r. Titel: Dyalogus.

Erlangen, UB, 575, 14. Jh., fol. 115r-116v. Praescriptio: Dyalogus Augustini inter sanctam animam et beatam virginem Mariam et est tractatus de originalibus sancti Augustini. Konsultiert in Reproduktionen (Mikrofilm).

Frankfurt a. M., StUB, Ms. Praed. 33, 15. Jh., fol. 25v-27r. Titel: De passione Domini.

Frankfurt a. M., StUB, Ms. Praed. 74, 15. Jh. (a. 1454), fol. 480r-481v. Titel: Contemplatio animae et planctus Sanctae Mariae.

Mainz, Bibliothek des Bischöflichen Priesterseminars, 34, 15. Jh. (a. 1462), fol. 203r-308r. Titel: Dialogus inter beatam virginem et animam fidelem quem Augustinus dicitur fecisse. 